\title{
Redox Interfaces Produce Halos of Altered Biogeochemical Reactivity in Alluvial Groundwater Sediments
}

\author{
KRISTIN BOYE ${ }^{1}$, TRISTAN BABEY ${ }^{3}$, NARESH KUMAR ${ }^{2}$, \\ VINCENT NOËL ${ }^{1}, Z_{A C H}$ PERZAN ${ }^{3}$, MAYA ENGEL $^{3}$, \\ BRADLEY B. TOLAR ${ }^{3}$, JOHN R. BARGAR ${ }^{1}$, SCOTT \\ FENDORF $^{3}$
}

${ }^{1}$ SLAC National Accelerator Laboratory, Menlo Park, USA.

${ }^{2}$ University of Vienna, Vienna, Austria.

${ }^{3}$ Stanford University, Stanford, U.S.A.

Sediment heterogeneities and redox interfaces are recognized as biogeochemical 'hot spots' exhibiting altered biogeochemical activity compared to their surroundings. Alluvial (floodplain) aquifers commonly exhibit fine-grained, organic-rich sediment layers and lenses within the predominantly coarse materials. Such features have previously been show to influence groundwater quality, altough there is some ambiguity in the literature as to what reaction and transport mechanisms that are responsible. Here we will provide experimental and modeling evidence showing that colloidal/particulate exchange across (or at) fine-anoxic and coarse-(sub)oxic interfaces results in profoundly altered biogeochemical reactivity extending like halos into the groundwater aquifer, causing significant changes in groundwater quality.

We conducted a set of dual-domain column experiments with natural sediments from a uranium and sulfate contaminated floodplain outside Riverton, WY, USA. The presence of fine-grained, organic-rich, reducing lenses in a sandy aquifer material exposed to aerated groundwater, propagated reducing conditions into the sandy material to an extent that could not be explained by aqueous phase chemistry. Mass balance calculations together with reactive transport modeling indicate that mass transfer of organic colloids/particles (possibly associated with minerals) must have occurred and resulted in nitrate, iron, and sulfate reduction by anaerobic microorganisms in the aquifer material. This 'exported reactivity' resulted in the establishment of a reducing halo extending up to 2 times the size of the initial reducing lens and led to highly elevated As concentrations, but decreased $U$ concentrations in the groundwater. These results are consistent with field-scale observations of reducing conditions extending outside of finegrained reducing zones into surrounding groundwater. Field scale reactive transport simulations further confirm that reducing halos develop around fine-grained reducing zones at a similar size ratio (i.e. $\sim 1: 2$ lens:halo) even when scaling to meters instead of centimeters. 